\title{
Chemical characterization and bioactive properties of a coffee-like beverage prepared from Quercus cerris kernels
}

\author{
Diana Pinto, (D) $\dagger^{\mathrm{a}, \mathrm{b}}$ Santiago Diaz Franco, $\dagger^{\mathrm{a}}$ Ana Margarida Silva, ${ }^{\mathrm{a}}$ \\ Snezana Cupara, (DD C Marijana Koskovac, ${ }^{\mathrm{C}}$ Ksenija Kojicic, ${ }^{\mathrm{C}}$ Sónia Soares, (D) a,d \\ Francisca Rodrigues, (D)*a,b Stefania Sut, ${ }^{e}$ Stefano Dall'Acqua ${ }^{f}$ and \\ M. Beatriz P. P. Oliveira (D) ${ }^{\text {a }}$
}

\begin{abstract}
In the present study, a coffee-like beverage was prepared from Quercus cerris seeds. Seeds presented $60.4 \%$ carbohydrates (of which $26.9 \%$ is fiber), $6.3 \%$ proteins and $4.0 \%$ fat. In the coffee-like beverage, the TPC and TFC were $2070.2 \mathrm{mg}$ GAE per $L$ and $285.3 \mathrm{mg} C E Q$ per $L$, respectively. The $I_{50}$ values determined using FRAP and DPPH assays were, respectively, $203.1 \mathrm{mg} \mathrm{L}^{-1}$ and $271.6 \mathrm{mg} \mathrm{L}^{-1}$. Concerning the reactive species scavenging capacity, the extract was more effective against $\mathrm{O}_{2}{ }^{\cdot-}, \mathrm{HClO}$ and ${ }^{*} \mathrm{NO}$ (namely, $\mathrm{IC}_{50}=$ $17.24 \pm 0.24 \mu \mathrm{g} \mathrm{mL}^{-1}, \mathrm{IC}_{50}=9.25 \pm 0.92 \mu \mathrm{g} \mathrm{mL} \mathrm{L}^{-1}$ and $\mathrm{IC}_{50}=0.65 \pm 0.06 \mu \mathrm{g} \mathrm{mL} \mathrm{L}^{-1}$ ). Qualitative and quantitative analyses by $1 \mathrm{D}-$ and 2D-NMR and LC-MS indicated high levels of ellagic acid and gallotannin or ellagitannin derivatives. The optimal range of non-cytotoxic concentrations in Caco-2 and HT29-MTX cell lines was between 0.1 and $1.0 \mu \mathrm{g} \mathrm{mL}^{-1}$. This is the first study that evaluates the $Q$. cerris seed extract as a beverage.
\end{abstract}

\section{Introduction}

Coffee is one of the most widely appreciated and consumed beverages in the world, mainly due to its stimulating effects. Depending on the country custom, this beverage is consumed in different quantities and forms, such as espresso or with milk. Likewise, coffee's attributes are widely appreciated by consumers, such as taste and aroma, being related to the roasting process. Due to this global interest, a current and highly discussed topic pertains the positive and negative effects of coffee consumption on human health as well as the possible alternatives to address the health related disadvantages. Modern consumers are much aware of potential health benefits of food and food ingredients,

\footnotetext{
${ }^{a}$ REQUIMTE/LAQV, Faculty of Pharmacy, University of Porto, Rua Jorge Viterbo Ferreira, 280, 4050-313 Porto, Portugal. E-mail: franciscapintolisboa@gmail.com; Fax: +351 226093390; Tel: +351220428500

${ }^{b} R E Q U I M T E / L A Q V$, Instituto Superior de Engenharia do Porto, Rua Dr. António Bernardino de Almeida, 4249-015 Porto, Portugal

${ }^{c}$ Faculty of Medical Sciences, Department of Pharmacy, University of Kragujevac, 34000 Kragujevac, Serbia

${ }^{d}$ REQUIMTE/LAQV, Faculty of Sciences, University of Porto, Rua do Campo Alegre, $s / n, 4169-007$ Porto, Portugal

${ }^{e}$ Department of Agronomy, Food, Natural resources, Animals and Environment, University of Padova, Via dell'Università 16, 35020 Legnaro, Italy

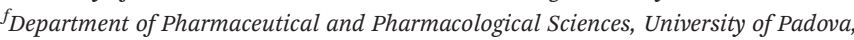
Via Marzolo 5, 35121 Padova, Italy

$\dagger$ The authors contributed equally to the present work.
}

demanding products with functional properties. In fact, different varieties of coffee-like substitutes such as chicory, malt or soluble cereal mixtures are available on the market. ${ }^{1}$ Their consumption is mainly related to the absence of caffeine and their richness in diverse bioactive compounds (such as antioxidants), being appropriate for consumption by consumers of all ages as well as by consumers with medical issues.

Quercus spp. is an evergreen or deciduous tree that comprises around 450 species, belonging to the Fagaceae family and representing an important group of temperate and tropical climatic areas. $^{2}$ These species produce a widely known fruit, frequently identified as acorn, with several uses, especially in the Mediterranean region. In Serbia, the Quercus cerris seeds are considered to be a resource with low value, being mainly used for making bread or to prepare a drink that can substitute traditional coffee. ${ }^{3}$ This traditional use as a coffee substitute began during the war periods, when coffee deprivation was most pronounced and oak kernels were cheap and easily available. ${ }^{4}$ Nevertheless, to the best of our knowledge, the information related to the bioactive compounds present in this coffee-like beverage, their scavenging capacity or their effects on intestinal cellsis scarce. The aim of this paper is to evaluate the roasted kernel nutritional composition as well as the antioxidant activity, phenolic composition, cell viability and toxic effects of the coffee-like beverage prepared with this ingredient in order to stimulate the valorisation of this under-explored natural resource as a new active ingredient by the food industry. 


\section{Materials \& methods}

\subsection{Plant material}

The plant material was collected on Kosmaj Mountain in the Sumadija region, Serbia, from autochthone sources during October and November 2016. The plant was identified as Quercus cerris at the Institute of Biology and Ecology, Faculty of Science, University of Kragujevac, Serbia, by standard botanical determination keys: Javorka and Csapody, Flora of the Republic of Serbia and Flora Europaea. Plant seeds were liberated from the shell and left in draft to dry. Afterwards, they were shortly exposed to heat $\left(200{ }^{\circ} \mathrm{C}\right)$ for 30 minutes and left to cool until being milled to powder (2-3 $\mathrm{mm})$.

\subsection{Macronutrient analysis}

The moisture content was instrumentally determined using a moisture analyzer (SMO 01, Scaltec Instruments, Germany). The ash content was evaluated by incinerating the sample in a muffle furnace at $550{ }^{\circ} \mathrm{C}$, according to the AOAC 923.03 method. $^{5}$ The protein content (nitrogen conversion factor 6.25) was quantified using the Kjeldahl procedure. Total fat was determined by the Soxhlet extraction method. ${ }^{6}$ The carbohydrate amount was obtained by difference. ${ }^{7}$ All analyses were performed in triplicate and the results are expressed as $g$ per $100 \mathrm{~g}$.

\subsection{Total vitamin $\mathbf{E}$ and vitamer quantification}

The lipid fraction for vitamin E quantification was obtained by Soxhlet extraction with petroleum ether $(4 \mathrm{~h})$. The chromatographic separation of the compounds was achieved on a normal phase Supelcosil ${ }^{\mathrm{TM}}$ LC-SI $(3 \mu \mathrm{m} ; 75 \times 3.0 \mathrm{~mm}$; Supelco, Bellefonte, PA, USA) according to the study by Alves et al. ${ }^{8}$ Chromatographic data were analyzed using JASCO Chrom NAV Chromatography Software (Jasco, Japan). The results are expressed in $\mathrm{mg}$ per $100 \mathrm{~g}$ of the sample. Analyses were performed in triplicate.

\subsection{Quercus cerris beverage preparation}

Powdered samples (a tablespoon with $\sim 8.8 \mathrm{~g}$ ) were subjected to extraction with $250 \mathrm{~mL}$ of water at $100^{\circ} \mathrm{C}$ for $5 \mathrm{~min}$. Extracts were filtered through Whatman no. 1 filter paper and kept under refrigeration $\left(4^{\circ} \mathrm{C}\right)$ prior to use. For the reactive oxygen and nitrogen scavenging assays (ROS and RNS, respectively) and cell viability assays, the extracts were lyophilized (Telstar, Cryodos, Spain) and stored at $-20^{\circ} \mathrm{C}$ until analysis.

\subsection{Determination of the total phenolic content (TPC)}

The Total Phenolic Content (TPC) was spectrophotometrically determined according to the Folin-Ciocalteu procedure ${ }^{9}$ with minor modifications. ${ }^{10}$ A calibration curve with gallic acid was used as the reference (linearity range $=5-100 \mathrm{mg} \mathrm{L}^{-1}, R^{2}>$ $0.999)$ to obtain a correlation between absorbance and standard concentration. The results were expressed as $\mathrm{mg}$ of gallic acid equivalents per litre of solution (mg GAE per L). The assay was carried out in triplicate.

\subsection{Determination of the total flavonoid content (TFC)}

The Total Flavonoid Content (TFC) was determined by a colorimetric method based on the formation of flavonoid-aluminum compounds, according to the method described by de Francisco et al. ${ }^{11}$ with minor modifications. A calibration curve was prepared with catechin (linearity range $=2.5-500 \mu \mathrm{g}$ $\left.\mathrm{mL}^{-1}, R^{2}>0.996\right)$. The results were expressed as $\mathrm{mg}$ of catechin equivalents per litre of solution ( $\mathrm{mg}$ CAE per L). This parameter was evaluated in triplicate.

\subsection{In vitro antioxidant activity}

The antioxidant activity was evaluated by $\mathrm{DPPH}^{*}$ radicalscavenging activity and ferric reducing antioxidant power (FRAP) as detailed in the following sections.

2.7.1. DPPH free radical scavenging assay. The reaction mixture was prepared directly on a 96 well microplate, according to the study by Almeida et al. ${ }^{12}$ The radical scavenging activity (RSA) was calculated as a percentage of DPPH discolouration using the equation: \% RSA $=\left[\left(A_{\mathrm{DPPH}}-A_{\mathrm{S}}\right) / A_{\mathrm{DPPH}}\right] \times$ 100 , where $A_{\mathrm{S}}$ is the absorbance of the solution when the sample extract has been added at a particular level, and $A_{\mathrm{DPPH}}$ is the absorbance of the DPPH solution. The extract concentration providing $50 \%$ of radical scavenging activity $\left(\mathrm{EC}_{50}\right)$ was calculated from the graph of RSA percentage against the extract concentration.

2.7.2. Ferric reducing antioxidant power (FRAP) assay. FRAP assay was carried out according to the method described by Benzie and Strain, ${ }^{13}$ with minor modifications. A calibration curve was prepared with ferrous sulphate $\left(\mathrm{FeSO}_{4} \cdot 7 \mathrm{H}_{2} \mathrm{O}\right)$ as the standard (linearity range: $25-500 \mu \mathrm{M}, R^{2}>0.985$ ). The radical scavenging activity (RSA) was calculated as a percentage. The extract concentration providing $50 \%$ of radical scavenging activity $\left(\mathrm{EC}_{50}\right)$ was calculated from the graph of RSA percentage against the extract concentration. This methodology was performed in triplicate.

\subsection{Identification of phenolic compounds by qualitative and quantitative analyses by ${ }^{1} \mathrm{H}$ NMR and LC-DAD-MS}

In order to assess the composition of the obtained beverages, ${ }^{1} \mathrm{H}-\mathrm{NMR}$ and $2 \mathrm{D}-\mathrm{NMR}$ experiments were performed. Extracts were prepared with $\mathrm{CDCl}_{3}$ and deuterated methanol, in order to observe the presence of constituents with different polarities. A beverage sample was prepared in deuterated water to assess the composition. Briefly, $100 \mathrm{mg}$ of powder was weighed in an Eppendorf tube and $2 \mathrm{~mL}$ of solvent was added for the extract analysis at different polarities. The Eppendorf tube was sonicated for 10 minutes, and centrifuged (18 900 rcf) and the liquid was transferred to a NMR tube for analysis. For the analysis of the beverage powdered sample, $500 \mathrm{mg}$ were subjected to solvent extraction by maceration with $10 \mathrm{~mL}$ of deuterated water at $100^{\circ} \mathrm{C}$ for $5 \mathrm{~min}$. The liquid was cooled and filtered and transferred to a NMR tube for analysis. NMR analysis was performed on a Bruker AVANCE III spectrometer operating at $400.13 \mathrm{MHz}$ for ${ }^{1} \mathrm{H}$-NMR. For solvent suppression, a noesy1d Bruker sequence was used. For 2D spectra, 
Heteronuclear Single Quantum Coherence-Distortionless Enhanced Polarization Transfer (HSQC-DEPT), Heteronuclear Multiple Bond Correlation (HMBC), Correlation Spectroscopy (COSY) and Total Correlation Spectroscopy (TOCSY) were performed using presaturation on the water signal for the identification of the class of compounds occurring in mixtures.

Afterwards, the quantitative analysis of phenolic derivatives was performed by LC-DAD-MS. An Agilent 1260 chromatograph (Santa Clara, CA, USA) equipped with a 1260 diode array (DAD) and a Varian MS-500 ion trap mass spectrometer was used. As the stationary phase, an Agilent Eclipse XDB C-18 $(3.0 \times 150 \mathrm{~mm}) 3.5 \mu \mathrm{m}$ was used. The mobile phases were water $0.1 \%$ formic acid (A) and acetonitrile (B). The elution gradient started at $90 \% \mathrm{~A}$ and then decreased to $0 \%$ over

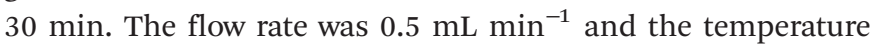
of the column was set at $30^{\circ} \mathrm{C}$. At the end of the column, a "T connector" split the flow rate to DAD and MS-500. The DAD detector was used to quantify galloyl derivatives. Gallic acid was used as the reference compound. The chromatograms were monitored at $280 \mathrm{~nm}$ and UV-Vis spectra were acquired in the range of 200-650 $\mathrm{nm}$. The sample injection volume was $20 \mu \mathrm{L}$. MS spectra were recorded in the $50-2000 \mathrm{~m} / \mathrm{z}$ range, using an ESI ion source operating in the negative ion mode. Fragmentation of the main ionic species was obtained by the turbo data depending scanning (TDDS) instrument function. The compound identification was performed based on the fragmentation spectra as well as in comparison with the literature. ${ }^{14}$ The phenolic compound quantification was performed by the calibration curve method by using the curve $y=38.387 x+$ $202.53\left(R^{2}=0.996\right)$ for gallic acid.

\subsection{Reactive oxygen species (ROS) and reactive nitrogen} species (RNS) scavenging assays

A Synergy HT Microplate Reader (BioTek Instruments, Inc., Winooski, VT, USA) was employed to evaluate the reactive species scavenging capacity. This plate was equipped with a thermostat and capable of measuring chemiluminescence, fluorescence and UV/Vis. Standards and samples were prepared according to the study by Marangi et al. ${ }^{15}$ and the same positive controls were used.

2.9.1. Superoxide radical scavenging assay. The superoxide anion radical $\left(\mathrm{O}_{2}{ }^{-}\right)$assay was performed according to the study by Marangi et al. ${ }^{15}$

2.9.2. Hydrogen peroxide scavenging assay. The hydrogen peroxide $\left(\mathrm{H}_{2} \mathrm{O}_{2}\right)$ scavenging assay was also performed according to the study by Marangi et al. ${ }^{15}$

2.9.3. Hypochlorous acid scavenging assay. The hypochlorous acid ( $\mathrm{HOCl})$ scavenging assay was based on a fluorescence methodology. ${ }^{15}$

2.9.4. Nitric oxide scavenging assay. The nitric oxide ( $\left.{ }^{*} \mathrm{NO}\right)$ scavenging assay used quercetin as the positive control, expressing the results as the inhibition (in percentage) of NOinduced oxidation of DAF-2, according to the study by Marangi et al. ${ }^{15}$

2.9.5. Peroxyl radical scavenging assay. The peroxyl radical (ROO`) scavenging assay was performed according to the study by Ou et $a .^{16}$ based on the monitoring effect of the tested extracts on the fluorescence decay resulting from ROO-induced oxidation of fluorescein. The standard control used was Trolox and the results were expressed as ROO-induced oxidation of fluorescein.

\subsection{Cell viability assays}

2.10.1. Cell lines, primary cell isolation and culture conditions. Caco-2 clone type C2BBe1 (passage 76-79) and HT29MTX (passage 33-35) cells are grown separately in tissue culture flasks (Orange Scientific, Belgium) in a complete medium, consisting of DMEM supplemented with $10 \%(\mathrm{v} / \mathrm{v})$ inactivated FBS, 1\% (v/v) L-glutamine, 1\% (v/v) non-essential amino acids and 1\% (v/v) antibiotic-antimitotic mixture (final concentration of $100 \mathrm{U} \mathrm{mL}^{-1}$ penicillin and $100 \mathrm{U} \mathrm{mL}^{-1}$ streptomycin) at $37{ }^{\circ} \mathrm{C}$ and $5 \% \mathrm{CO}_{2}$ under a water saturated atmosphere in an incubator (CellCulture ${ }^{\circledR} \mathrm{CO}_{2}$ Incubator, ESCO GB Ltd, UK). At 90-95\% confluence, both cell lines were harvested using trypsin (Invitrogen) and re-plated in T125 flasks.

2.10.2. MTT assay. The sample effect on cell viability was measured using the 3-(4,5-dimethylthiazol-2-yl)-5-(3-carboxymethoxyphenyl)-2-(4-sulfophenyl)-2H-tetrazolium (MTT) conversion assay. For that, Caco-2 and HT29-MTX cells were seeded separately in 96-well microplates at $25 \times 103$ cells per well in supplemented DMEM and incubated for $24 \mathrm{~h}$ at $37^{\circ} \mathrm{C}$ in a 5\% CO2 environment. The sample and negative (DMEM) and positive controls $(1 \%(\mathrm{v} / \mathrm{v})$ Triton $\mathrm{X}-100)$ were added in triplicate to the cell culture. The medium was changed and the cells were treated with sample/controls for $24 \mathrm{~h}$. Each treatment was tested in six individual wells. The supernatant was removed and the MTT solution was added to each well and incubated for $3 \mathrm{~h}$ at $37^{\circ} \mathrm{C}$ to allow the formation of formazan crystals. After that, the medium was removed and the blue formazan crystals were eluted from cells using $150 \mu \mathrm{L}$ of DMSO. The absorbance was measured at $590 \mathrm{~nm}$ with background subtraction at $630 \mathrm{~nm}$. Experiments were carried out in triplicate.

\subsection{Statistical analysis}

All experimental analyses were performed in triplicate and means and standard deviations were calculated. Statistical analysis of the data was carried out using IBM SPSS Statistics Version 24.0 (SPSS, Inc. Chicago, IL). The $\mathrm{IC}_{50}$ values of ROS and RNS scavenging activity were calculated from the curves of percentage of inhibition versus antioxidant concentration, using the GraphPad Prism 5 software.

\section{Results and discussion}

\subsection{Macronutrient analysis}

The nutritional profile of the kernels analysed in this study is described in Table 1. These seeds are composed of a high amount of carbohydrates (60.4\%), of which $26.9 \%$ is fiber. Kernels also present a considerable source of proteins $(6.3 \%)$, being poor in lipids (4.0\%). 
Table 1 Nutritional composition of $Q$. cerris seeds (mean \pm standard deviation). Values are an average of three individual samples $(n=3)$. nd - not detectable

\begin{tabular}{ll}
\hline & Q. cerris seeds \\
\hline Moisture & $6.7 \pm 0.13$ \\
Carbohydrates $^{a}$ & $60.4 \pm 0.1$ \\
Of which fiber $^{a}$ & $26.9 \pm 0.2$ \\
Proteins $^{a}$ & $6.3 \pm 0.2$ \\
Lipids $^{a}$ & $4.0 \pm 0.06$ \\
$\operatorname{Ash}^{a}$ & $2.4 \pm 0.00$ \\
Vitamers $(\mathbf{m g}$ per $\mathbf{1 0 0} \mathbf{g})$ & \\
$\alpha$-Tocopherol & $7.670 \pm 0.100$ \\
$\beta$-Tocopherol & nd \\
$\gamma$-Tocopherol & $5.765 \pm 0.075$ \\
$\delta$-Tocopherol & $0.397 \pm 0.02$ \\
$\alpha$-Tocotrienol & $1.616 \pm 0.095$ \\
$\beta$-Tocotrienol & nd \\
$\gamma$-Tocotrienol & nd \\
$\delta$-Tocotrienol & nd \\
Total & $15.448 \pm 0.19$ \\
& \\
${ } \%$ in dry weight. & \\
&
\end{tabular}

The results are in accordance with those published by Vinha et al., who evaluated Q. suber, Q. faginea, Q. nigra and Q. ilex kernels, describing a high amount of carbohydrates (ranging between 86 and $89 \mathrm{~g}$ per $100 \mathrm{~g}$ dry weight (dw)), followed by proteins (between 5 and $7 \mathrm{~g}$ per $100 \mathrm{~g} \mathrm{dw}$ ). ${ }^{2}$ Similarly, the lipidic content is low. ${ }^{10}$ In another study, Nieto et al. also reported a low protein content for Spanish acorns produced by Q. rotundifolia (holm oak) (4.8 g per $100 \mathrm{~g} \mathrm{dw}$ ) and Q. suber (6.3 g per $100 \mathrm{~g} \mathrm{dw}) .{ }^{17}$ In 2015 , Li et al. stated that Q. glandulifera seeds had a low fat value $(4.20 \mathrm{~g}$ per $100 \mathrm{~g} \mathrm{dw})$ and a protein content of $10.16 \mathrm{~g}$ per $100 \mathrm{~g} \mathrm{dw},{ }^{18}$ being in line with the present results.

The vitamin E content of kernels is also summarized in Table 1. It is well known that Vitamin $\mathrm{E}$ is the major lipidsoluble antioxidant in the cell defence system, being composed of eight naturally occurring and structurally related vitamers, namely four tocopherols ( $\alpha-, \beta-, \gamma^{-}$, and $\left.\delta_{-}\right)$and four tocotrienols $\left(\alpha-, \beta-, \gamma^{-}\right.$, and $\left.\delta^{-}\right)$. $\alpha$-Tocopherol is the most biologically active form and the biological effects are generally due to its antioxidant properties. The main vitamer present in kernels was $\alpha$-tocopherol (7.670 mg per $100 \mathrm{~g}$ ), followed by $\gamma$-tocopherol (5.765 mg per $100 \mathrm{~g}$ ) and $\alpha$-tocotrienol (1.616 mg per $100 \mathrm{~g}$ ). $\delta$-Tocopherol was the minor one $(0.397 \mathrm{mg}$ per $100 \mathrm{~g})$. $\beta$-Tocopherol, $\beta$-tocotrienol, $\gamma$-tocotrienol and $\delta$-tocotrienol were not detected. Once again, these results are in line with those of Vinha et al., who reported that $\alpha$-tocopherol and $\gamma$-tocopherol were the predominant vitamers in $Q$. suber, $Q$. faginea, $Q$. nigra and $Q$. ilex acorns. ${ }^{2}$ Comparatively to $Q$. glandulifera seeds, the total vitamin $\mathrm{E}$ is higher. Li et al. reported a content of $10.78 \mathrm{mg}$ per $100 \mathrm{~g}$ for this species. ${ }^{18}$

\subsection{Total phenolic and total flavonoid contents and antioxidant activity}

The TPC, TFC and antioxidant activity of the coffee-like beverage were evaluated. The TPC was $2070.21 \pm 69.02 \mathrm{mg}$ GAE per
L, while the TFC was $285.27 \pm 10.96 \mathrm{mg}$ CAE per L. To screen the antioxidant properties, two different assays were employed: scavenging activity on $\mathrm{DPPH}^{*}$ radicals and the ferric reducing antioxidant power (FRAP). In what concerns DPPH, the $\mathrm{IC}_{50}$ value was $271.61 \pm 24.61 \mu \mathrm{g} \mathrm{mL}^{-1}$, while for FRAP the result was $203.11 \pm 3.56 \mu \mathrm{g} \mathrm{mL} \mathrm{m}^{-1}$. To the best of our knowledge, this is the first study that evaluates the antioxidant content of a coffee-like beverage prepared from kernels. Compared with coffee silverskin for example, the TPC and TFC are considerably higher. ${ }^{18}$ Costa et al. reported that the higher TPC obtained was $310 \mathrm{mg}$ GAE per L, using a hydroalcoholic mixture $(50: 50)$ at $50{ }^{\circ} \mathrm{C}$ or $60{ }^{\circ} \mathrm{C}$ for $90 \mathrm{~min} .{ }^{19}$ In what concerns the TFC, Costa et al. stated that the highest value (144 mg CAE per L) was achieved with the hydroalcoholic extract (25\% water : $75 \%$ ethanol) at $60{ }^{\circ} \mathrm{C}$ for $90 \mathrm{~min} .{ }^{19}$ The results reported in the present study are considerably higher. Also, it should be highlighted that in the present study the solvent used was water.

Regarding the DPPH and FRAP assay, our results are shown as $\mathrm{IC}_{50}$. Once again, compared with those of Costa et al., the present results are considerably better. The highest DPPH scavenging ability reported by the authors was $416 \pm 4.2 \mathrm{mg}$ Trolox Equivalents (TE) per L, obtained with a hydroalcoholic extract (25\% water : $75 \%$ ethanol) at $30{ }^{\circ} \mathrm{C}$ during $60 \mathrm{~min}$. In what concerns the FRAP assay, the best value determined by Costa et al. was $1700 \mathrm{mg}$ ferrous sulphate equivalents (FSE) per $\mathrm{L}$, once again with the hydroalcoholic extract. The authors did not achieve the $\mathrm{IC}_{50}$ results. In another study, Rocha-Guzmán et al. evaluated water infusions of mature and fresh $Q$. resinosa leaves, reporting higher $\mathrm{IC}_{50}$ values for the DPPH assay, namely 507 and $548 \mu \mathrm{g} \mathrm{mL}{ }^{-1}$ for fresh and mature leaves. ${ }^{20}$

When a regression analysis was performed between the values of $\mu \mathrm{mol}$ Trolox equivalents per $\mathrm{L}$ and the $\mathrm{IC}_{50}$ determined for the FRAP assay, a positive correlation is achieved $\left(R^{2}=0.570 ; p<0.01\right)$. Nevertheless, when the regression analysis is performed between the values of $\mu \mathrm{mol}$ Trolox equivalents per $\mathrm{L}$ and the $\mathrm{IC}_{50}$ determined for the DPPH assay, a high positive correlation is obtained $\left(R^{2}=0.811 ; p<0.001\right)$. Also, the correlation between the mg Catechin equivalents per $\mathrm{L}$ and the $\mathrm{IC}_{50}$ determined in the DPPH assay is extremely positive $\left(R^{2}=\right.$ 0.969; $p<0.01$ ), while for FRAP the Pearson correlation is negative $\left(R^{2}=-0.262 ; p<0.01\right)$. Thus, according to these results, the antioxidant activity observed could be due to the presence of phenolic compounds, particularly flavonoids. Nevertheless, the interpretation of results needs to be performed with precaution, as the final effects of a complex extract result from the combinatory and synergic actions of all its constituents. In that way, the identification and quantification of phenolic compounds are extremely important.

\section{3. $\quad{ }^{1} \mathrm{H}-\mathrm{NMR}$ and LC-MS analysis}

As a preliminary investigation of the kernel composition, a ${ }^{1} \mathrm{H}$-NMR analysis was performed to assess the presence of different classes of constituents. For this reason, a vegetal material was extracted with deuterated chloroform (Fig. 1(a)) and deuterated methanol in order to evaluate the most lipo- 
(a)

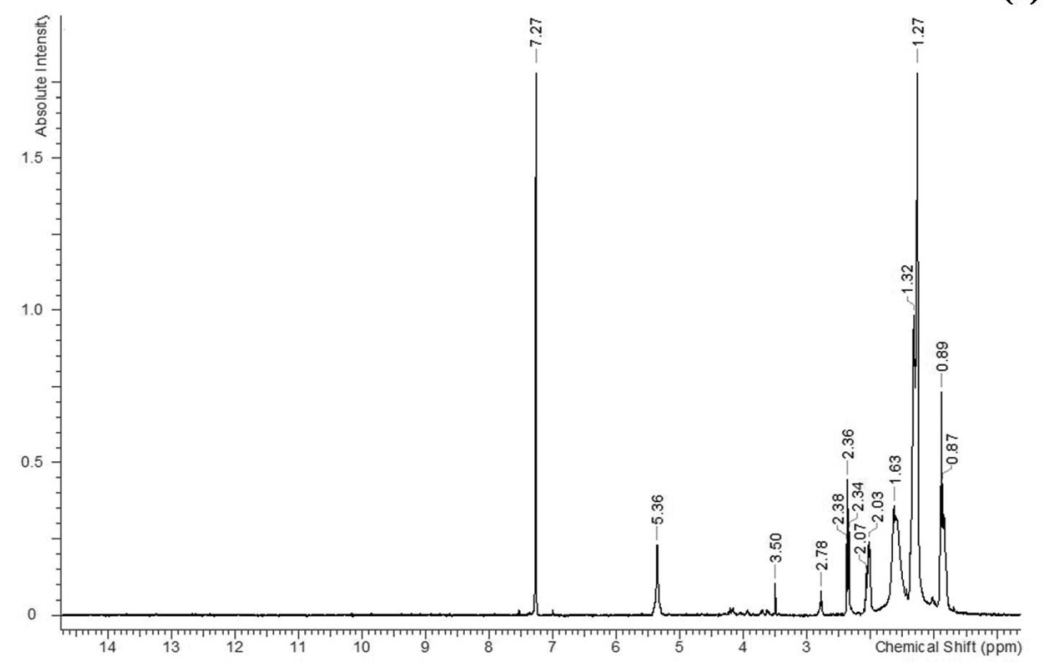

(b)

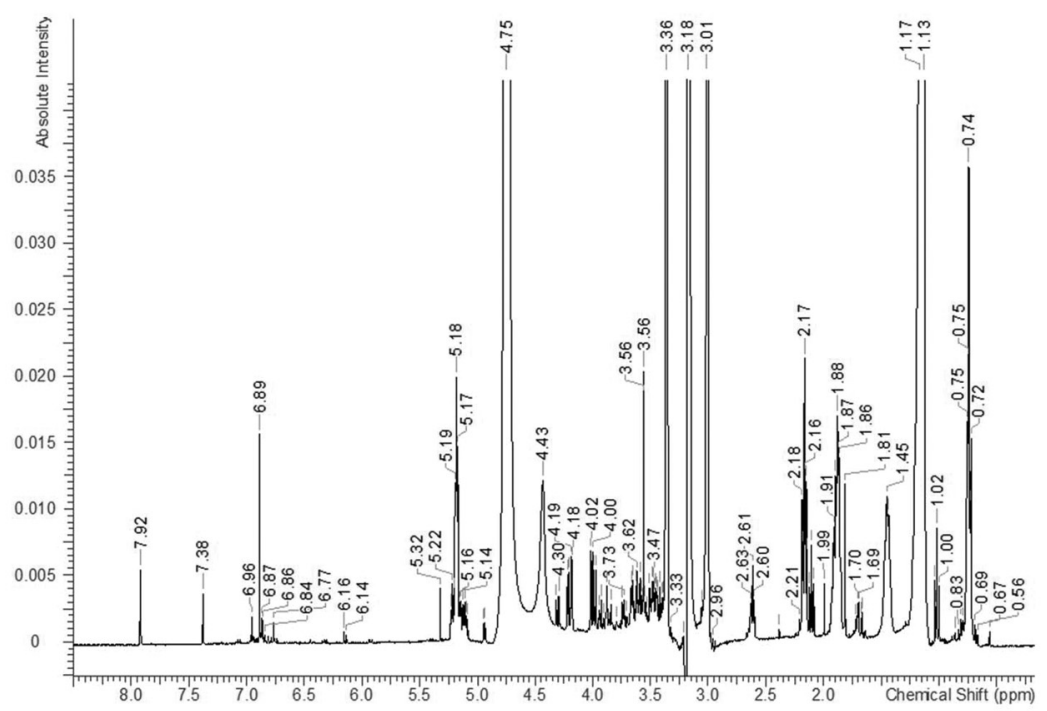

(c)

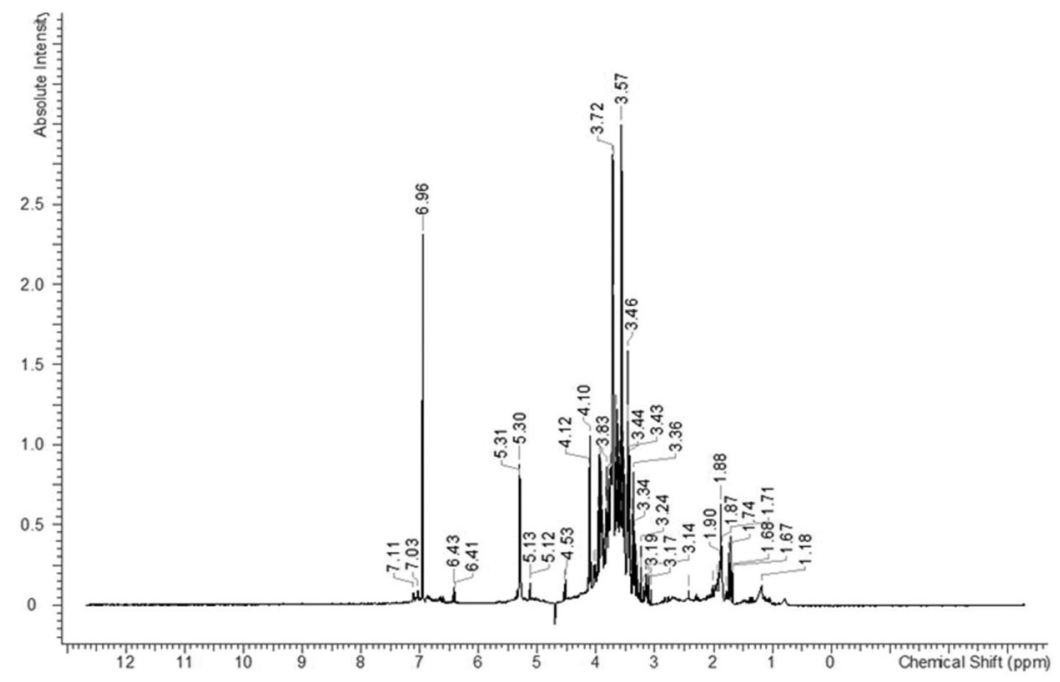

Fig. $1{ }^{1} \mathrm{H}$-NMR of the extract obtained in deuterated chloroform (a), in deuterated methanol (b) and in deuterated water with presaturation of the water solvent (c). 
philic constituents as well as the compounds with intermediate polarity. Additionally, a sample was prepared using deuterated water (Fig. 1(b)) in order to analyse the final product of the trial.

The fraction soluble in deuterated chloroform presents a ${ }^{1} \mathrm{H}$-NMR spectrum that clearly shows the presence of fatty acid and lipid constituent fractions, namely the triplet at $\delta 0.74$ ascribable to terminal methyl groups, the large signals at $\delta 1.27$ and $1.63 \mathrm{ppm}$ due to $\mathrm{CH}_{2}$ chains, the multiplet at $\delta 2.03$ supporting the $\mathrm{CH}_{2}$ vicinal to double bonds and the triplet at $\delta 2.36$ ascribable to $\mathrm{CH}_{2}$ vicinal to the carboxyl function. A broad signal at $\delta 5.36$ supports the presence of double bonds suggesting the presence of an unsaturated lipid fraction. The spectral region of aromatic and lower fields (6-8 ppm) did not reveal the presence of other constituents in a significant amount.

Regarding the methanolic soluble fraction, it was possible to observe the presence of fatty acid signals, such as in the aqueous extract, but also a crowded region of signals in the ppm ranging from $\delta 3.0$ to 5.0 supporting the presence of sugar residues. In particular, the doublets at $\delta 4.93$ and $\delta$ 4.29 may be assigned to anomeric proton signals of sugars. Furthermore in the spectral region from $\delta 5.8$ to 7.8, signals ascribable to olefinic and aromatic protons can be observed, as well as singlets at $\delta 9.4$ and 9.3 suggesting the presence of aldehyde groups.

The sample prepared as a coffee-like beverage but using deuterated water (Fig. 1(c)) presents a different ${ }^{1} \mathrm{H}-\mathrm{NMR}$ spectrum, showing almost the absence of fatty acid signals, while the crowded region at $\delta 3-5$ ppm supports the presence of sugar derivatives.

An intense signal in the aromatic region was a singlet at $\delta 6.96$ that in the HSQC spectrum acquired with water presaturation correlates with carbon resonance at $\delta$ 108.3. Other significant $\mathrm{H}-\mathrm{C}$ direct connections were observed in the HSQC between signals respectively at $\delta 3.50-60.0$ and $\delta$ 3.52-62.5; from signals in the range $\delta 3.65-3.75$ with carbon resonances 74.1-79.0 and from $\delta 3.50-3.56$ with carbon resonances at $\delta 84.0$ (Fig. 2). Further signals ascribable to anomeric protons are detected as doublets at $\delta$ 5.27-91.1 and $\delta$ 5.23-99.2 (Fig. 2(a)).

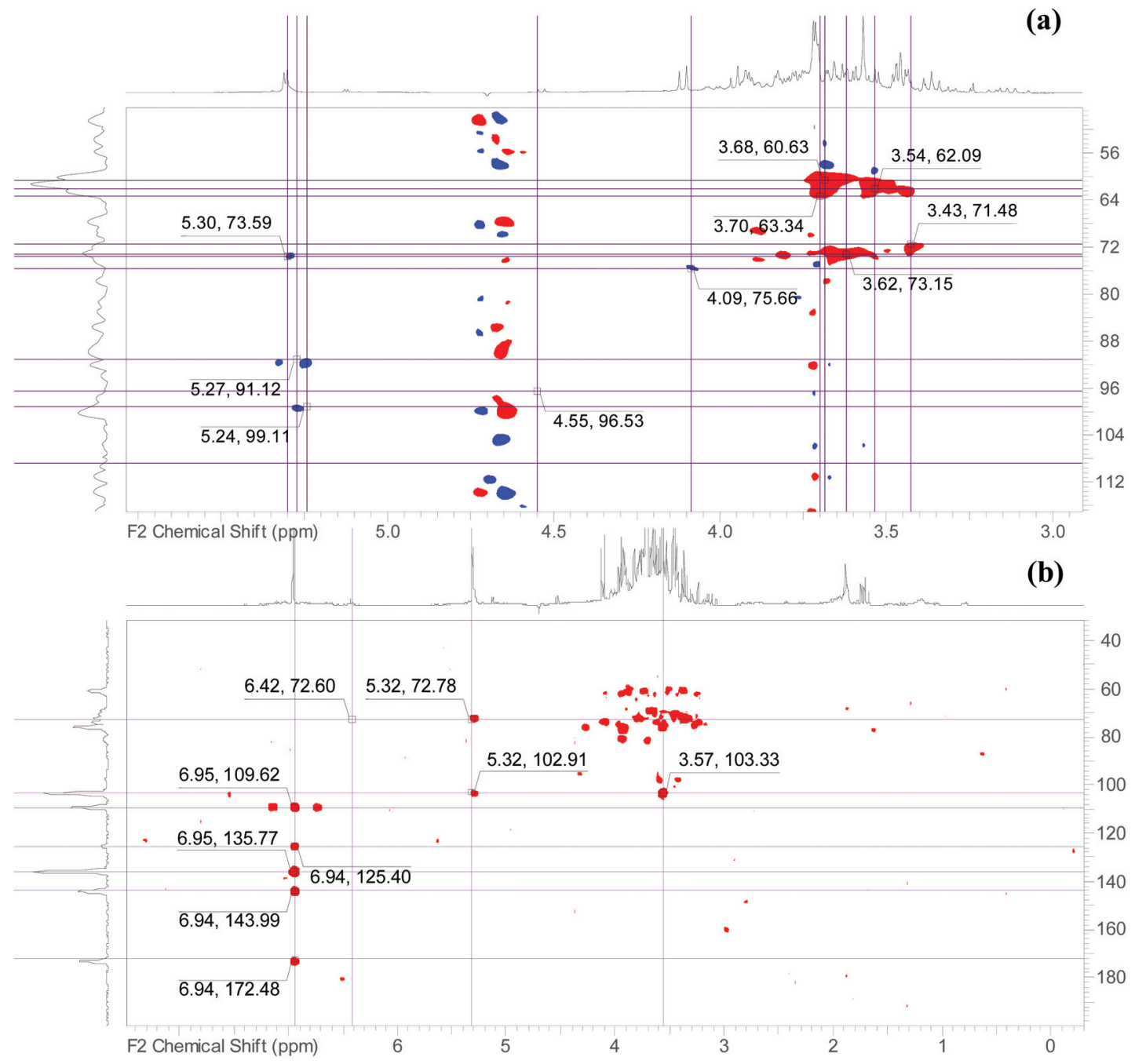

Fig. 2 HSQC (a) and HMBC (b) of the extract obtained in deuterated water. 
Furthermore, a signal supporting the presence of an esterified $\mathrm{CHOH}$ group is revealed at $\delta$ 5.31-73.3. In the aromatic region, signals are observed at $\delta$ 6.98-125.3, 6.79-96.5 and $\delta$ 6.90-108.3; no proton signals in the region from $\delta 7.5$ to $10.0 \mathrm{ppm}$ were observed. HMBC correlations were observed from the singlet at 6.93 with carbon resonances at $\delta 109.6,125.4$, 135.7, 143.9 and 172.5 supporting the presence of an ester derivative of gallic acid with saccharides as glucose (Fig. 2(b)).

The preliminary analysis by NMR in seeds revealed the presence of a series of aromatic derivatives, fatty acids and sugars. In what concerns the coffee-like beverage, the main classes of extracted compounds were phenolics and sugars. Sugar residues can be ascribed to hexose as glucose or epimers as well as 6-deoxy hexose characterized by the signals at $\delta 1.70-1.73$ that are correlated in the HSQC with resonances at $\delta 32.6$, while in the HMBC those signals correlate with carbon resonances at $\delta 79.5$ and 68.0.

Further data were obtained using LC-DAD-ESI-MS ${ }^{n}$ in the negative ionization mode. Two prevalent peaks at $280 \mathrm{~nm}$ and some minor peaks presenting the same UV spectrum, mainly ellagic acid and gallotannin or ellagitannin derivatives (Table 2), were identified on the basis of their $\mathrm{MS}^{n}$ spectra and comparison with the literature. The most abundant observed $\mathrm{m} / \mathrm{z}$ and relatively low energy collision induced dissociations occurring in the ion trap are summarised in Fig. 3 and Table 2.

Quantification was performed using a diode array detector and gallic acid as the reference compound. Ellagic acid was coeluted with tetragalloyl glucose derivatives and its quantification was not possible by LC-DAD. The most abundant constituents are tetragalloyl hexose and dihydroxymethylbenzoyl tetragalloylglucose. On the dried extracts, the amount of the phenolic constituents is about $11 \%$ (w/w dry weight).

The most abundant constituents were tetragalloyl hexose $(6.79 \mathrm{w} / \mathrm{w})$ and dihydroxymethylbenzoyl tetragalloylglucose (1.93 $\mathrm{w} / \mathrm{w})$, while trigalloyl hexose was the less abundant $(0.05 \mathrm{w} / \mathrm{w})$.

\subsection{Scavenging of ROS and RNS}

The results of ROS and RNS scavenging activity are presented in Table 3.
Currently, the consumer concerns related to aging and health have generated deep interest in the food composition, namely bioactive compounds that could increase not only the nutritional value but also the health status. ${ }^{11}$ ROS and RNS are involved in important physiological processes, such as the inflammatory response, cellular signaling systems or even organism defense. When an imbalance occurs between the antioxidant system and the ROS/RNS production, an "oxidative stress" stage occurs, affecting major cellular components such as lipids, proteins or DNA and leading to the development of different diseases. Different radicals normally occur in humans. The oxygen molecule is the most reactive. As it is possible to observe in Table 2, the coffee-like beverage showed a notable capacity to scavenge all the tested ROS and RNS in a concentration-dependent manner. The $\mathrm{IC}_{50}$ values determined were found at low concentrations, particularly for the superoxide anion radical and the nitric oxide assays. $\mathrm{O}_{2}{ }^{--}$is an important precursor of a variety of powerful oxidants. The $\mathrm{IC}_{50}$ determined for this ROS was $17.24 \mu \mathrm{g} \mathrm{mL} \mathrm{m}^{-1}$. This value is considerably lower than the one reported for the positive control used. $\mathrm{H}_{2} \mathrm{O}_{2}$, together with $\mathrm{O}_{2}{ }^{--}$, is another species responsible for generating reactive and potent species, such as $\mathrm{HO}^{\circ}$ and HOCl. In fact, $\mathrm{H}_{2} \mathrm{O}_{2}$ may cross cell membranes and react with transition metals by the Fenton reaction, producing ${ }^{\circ} \mathrm{OH}$, which is considered one of the most reactive species. The $\mathrm{IC}_{50}$ determined for $\mathrm{H}_{2} \mathrm{O}_{2}$ was $275.70 \mu \mathrm{g} \mathrm{mL}{ }^{-1}$. This result is higher than the positive control used $\left(93.84 \mu \mathrm{g} \mathrm{mL} \mathrm{m}^{-1}\right)$. Regarding HClO, which is formed in neutrophils from the reaction between $\mathrm{H}_{2} \mathrm{O}_{2}$ and chloride ions catalysed by myeloperoxidase enzyme, the $\mathrm{IC}_{50}$ determined was $9.25 \mu \mathrm{g} \mathrm{mL}{ }^{-1}$. This species is extremely reactive with biomolecules particularly during the inflammatory process. In what concerns nitric oxide, this reactive nitrogen species is the conversion result of L-arginine to L-citrulline by nitric oxide synthase, being in high concentrations associated with inflammatory processes and cell effects. The $\mathrm{IC}_{50}$ determined for this species was $0.65 \mu \mathrm{g} \mathrm{mL} \mathrm{m}^{-1}$, higher than that for quercetin. Finally, the peroxyl radical is generated during the lipid oxidation chain reactions having the ability to react with contiguous molecules. The results

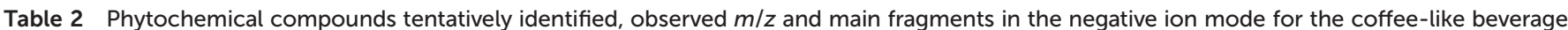
by LC-DAD-ESI-MS

\begin{tabular}{|c|c|c|c|c|c|}
\hline No. & $t_{\mathrm{R}}(\min )$ & Compound & $\operatorname{MS}[\mathrm{M}-\mathrm{H}]^{-}$ & Fragments & $\%(\mathrm{w} / \mathrm{w})$ \\
\hline 1 & 1.5 & Galloyl hexose & 341.5 & 179 & 1.02 \\
\hline 2 & 3.2 & Galloyl derivative & 493 & 313 & 0.62 \\
\hline 3 & 12.4 & Trigalloyl hexose & 635 & $465,483,313$ & 0.20 \\
\hline 4 & 15.2 & Trigalloyl hexose & 635 & $465,483,313$ & 0.05 \\
\hline 5 & 15.8 & Trigalloyl hexose & 635 & $465,483,313$ & 0.16 \\
\hline 6 & 18.5 & Tetragalloyl hexose & 787 & $617,573,465,447,313,170$ & 0.47 \\
\hline 7 & 19.9 & Tetragalloyl hexose & 788 & $617,573,465,447,313,171$ & 0.47 \\
\hline 8 & 19.6 & Tetragalloyl hexose & 788 & $617,573,465,447,313,171$ & 6.79 \\
\hline 9 & 19.7 & Ellagic acid & 301 & $229,201,186,174$ & $a$ \\
\hline 10 & 17.1 & Dihydroxymethylbenzoyl tetragalloylglucose & 937 & $857,785,767,741,617,599,589,465$ & 0.16 \\
\hline 11 & 19.5 & Dihydroxymethylbenzoyl tetragalloylglucose & 938 & $857,785,767,741,617,599,589,466$ & 1.93 \\
\hline \multicolumn{5}{|c|}{ Total content } & 11.87 \\
\hline
\end{tabular}

${ }^{a}$ Ellagic acid was not quantified by DAD because it overlapped with a larger peak of tetragalloyl hexose. 


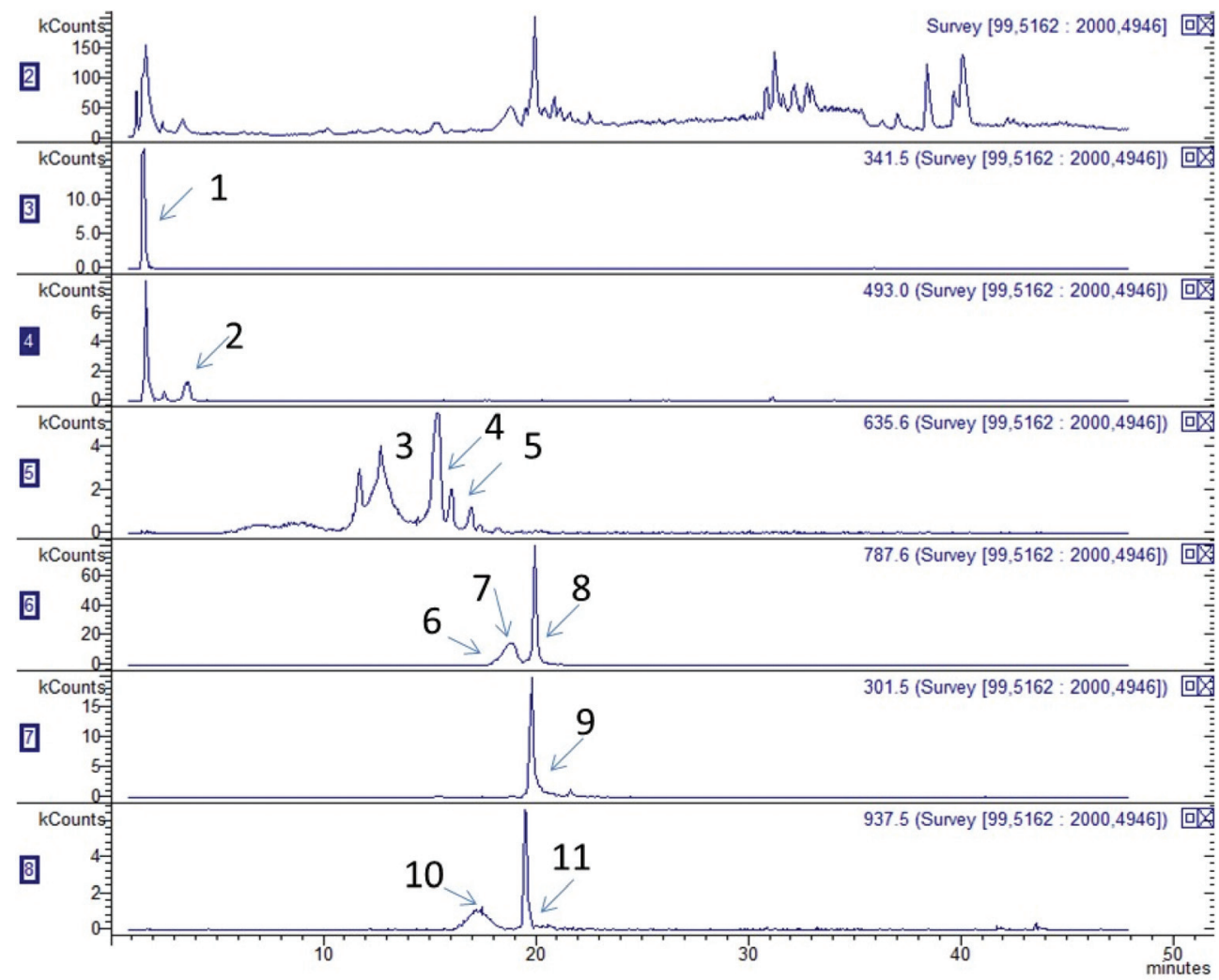

Fig. 3 LC-MS of the extract obtained with water. Chromatograms corresponding to main ionic species namely $\mathrm{m} / \mathrm{z} 341,493,365,787,301$ and 937 are shown. Peaks: see Table 2.

Table 3 Superoxide anion radical $\left(\mathrm{O}_{2}{ }^{-}\right)$, hydrogen peroxide $\left(\mathrm{H}_{2} \mathrm{O}_{2}\right)$, hypochlorous acid $(\mathrm{HOCl})$, peroxyl radical (ROO'), nitric oxide ('NO) and peroxynitrite $\left(\mathrm{ONOO}^{-}\right)$scavenging capacities of the extract. Values are expressed as mean \pm standard deviation $(n=3)$. Different letters in the same column indicate significant differences between mean values $(p<0.05)$

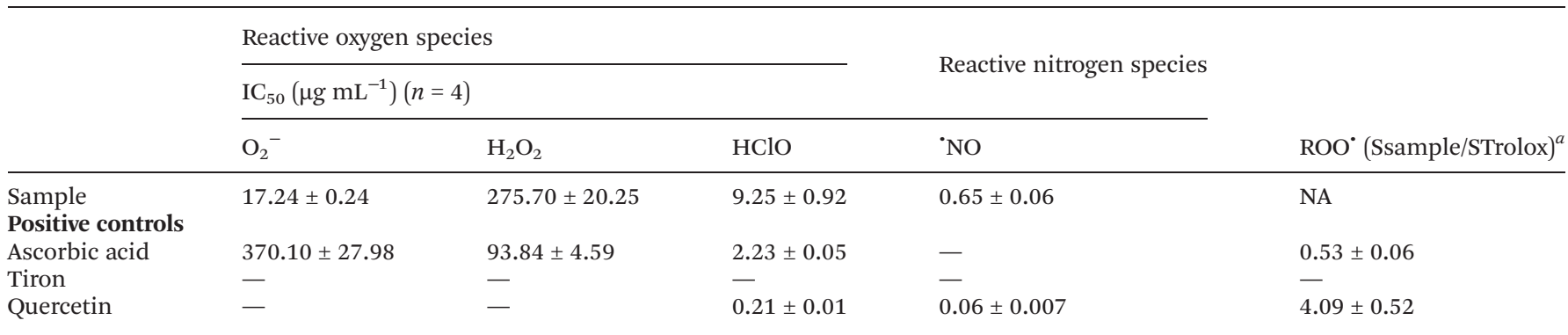

$\mathrm{IC}_{50}=$ in vitro concentration required to decrease in $50 \%$ the reactivity of the studied reactive species in the tested media (mean \pm standard error of the mean; $n=3)$; NA: No activity was determined up to the highest tested concentration $\left(1 \mathrm{mg} \mathrm{mL}^{-1}\right)$. ${ }^{a}$ Ssample $=$ slope of extract curves. STrolox = slope of the trolox curve.

obtained in the present study showed that the coffee-like beverage is not able to scavenge $\mathrm{ROO}^{\circ}$ in in vitro systems.

The activity observed for all species results is a consequence of the action of the several bioactive molecules present on the extract. The notable scavenging effect of the coffee-like beverage, especially against $\mathrm{O}_{2}{ }^{--}$and ${ }^{\circ} \mathrm{NO}$, was probably due to the high content of bioactive compounds, particularly phenolic compounds. Recently Gamboa-Gómez et al. assessed the in vitro and in vivo antioxidant effects of oak leaf (Q. convallata and $Q$. arizonica) infusions and fermented beverages. ${ }^{21}$ The authors reported a high antioxidant potential (ranging between 11.02 and $53.31 \mu \mathrm{M}$ Trolox equivalents per $\mu \mathrm{g}$ dry sample, respectively for the $Q$. arizonica fermented beverage and $Q$. convallata leaves infusion, respectively) and scavenging activity for radicals such as peroxyl (between 0.10 and $0.45 \mu \mathrm{M}$ Trolox equivalents per $\mu \mathrm{g}$ dry sample) and peroxynitrite anions (from 8.40 to $15.98 \mu \mathrm{M}$ Trolox equivalents per $\mu \mathrm{g}$ dry sample). Nevertheless, compared with results in Table 2, the values 
reported for the scavenging activity were lower than the ones obtained in this study. The authors did not achieve the $\mathrm{IC}_{50}$. In another study, Rodrigues et al. evaluated the in vitro antioxidant and anti-inflammatory properties of Limonium algarvense flower infusions and decoctions. ${ }^{22}$ The $\mathrm{IC}_{50}$ reported for the hydroxyl radical was $2.00 \mathrm{mg} \mathrm{mL}^{-1}$ for the $L$. algarvense infusion while for the decoction it was $1.82 \mathrm{mg} \mathrm{mL}^{-1}$. In what concerns the superoxide radical, the values ranged from 0.30 to $0.32 \mathrm{mg} \mathrm{mL}^{-1}$, respectively, for the decoction and the infusion. All results were considerably higher than the ones presented for the coffee-like beverage (Table 2).

\subsection{Effects of extracts towards Caco-2 and HT29-MTX cells}

In order to evaluate the effects of the coffee-like beverage on intestinal cells, the extract was added at different concen-

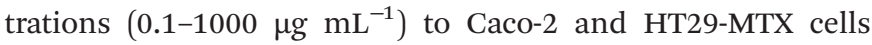
(Fig. 4). Both cell lines were selected to mimic the intestinal model, particularly the small intestine, since it is in this location that the majority of the absorption process occurs.

According to the obtained results, the coffee-like beverage caused a decrease in Caco- 2 cell viability. The concentration of 10 and $100 \mu \mathrm{g} \mathrm{mL}{ }^{-1}$ leads to a cell viability of, respectively, 64.66 and $67.32 \%$ while the concentration of $1000 \mu \mathrm{g} \mathrm{mL}$ leads to a cell viability of $47.07 \%$. On the other hand, the concentrations of 0.1 and $1.0 \mu \mathrm{g} \mathrm{mL}^{-1}$ did not decrease the cell viability. In contrast, the HT29-MTX viability decreased with all concentrations tested in a similar way. It was around $70 \%$ for all concentrations, except $1000 \mu \mathrm{g} \mathrm{mL}^{-1}$ (in this case, the cell viability was $58.51 \%$ ). These results support the evidence reported by Almeida et al. as well as by de Francisco et al. that Caco-2 cells are more sensitive cells than HT29-MTX. ${ }^{11,12}$ Both authors evaluated the extract effects on these two cell lines, reporting that Caco-2 cells are more sensitive. Taking into account the results observed for both cell lines, the optimal range of non-cytotoxic concentrations of the coffee-like beverage should be between 0.1 and $1.0 \mu \mathrm{g} \mathrm{mL}^{-1}$ for further experiments. Recently, Martins-Gomes et al. tested decoctions and

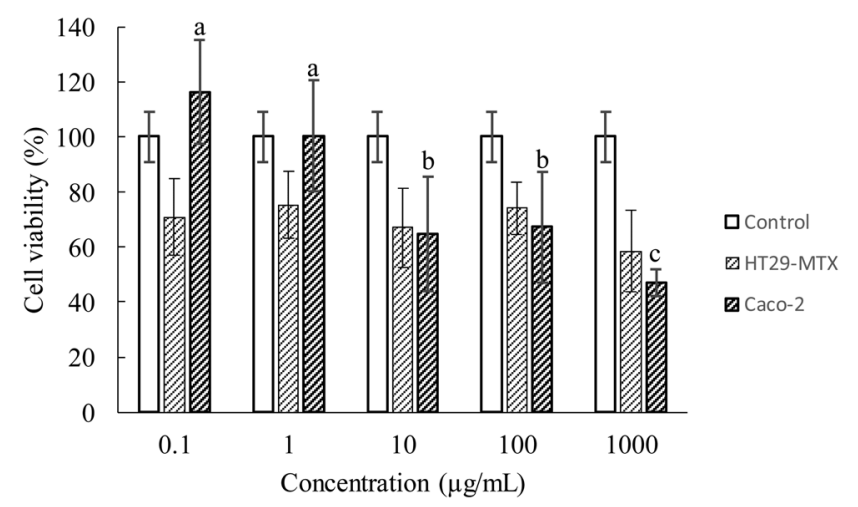

Fig. 4 Effect of coffee-like beverage exposure on the viability of HT29MTX and Caco- 2 cells at different concentrations, as measured by the MTT assay. Values are expressed as means \pm SD $(n=6)$. Different letters on the same cell line mean statistical differences between concentrations $(p<0.05)$. hydroethanolic extracts of Thymus carnosus Boiss in two breast cancer cell lines (MCF-7 and BT-474). ${ }^{23}$ After 24 hours of contact, the $\mathrm{IC}_{50}$ values for the decoction were 533.87 and 841.28 $\mu \mathrm{g} \mathrm{mL}{ }^{-1}$, respectively, for MCF-7 and BT-474 cells, while for the infusion these values were almost 10 times lower (respectively 86.87 and $39.91 \mu \mathrm{g} \mathrm{mL}{ }^{-1}$ for MCF-7 and BT-474 cells). ${ }^{23}$ Thus, the coffee-like beverage was considerably safer than these beverages.

In fact, growing interest in the relationship between food and health has been observed in the last decade in order to achieve a healthy and longer life, changing the food consumers' behaviour and leading to the development of functional foods. These functional food characterization studies are firstly based on the identification of bioactive compounds and then on evidence of their benefits to human health. Besides the role played by some bioactive compounds already reported in the previous sections, their antioxidant properties against reactive oxygen/nitrogen species may be associated with the reduction of the risk of developing several diseases such as cancer or neurodegenerative disorders. The employment of in vitro assays to observe potential benefits is an option. To exert their biological functions, these compounds must be released from foods and become available to absorption by the human body which can be observed performing intestinal assays using 3D models, for example. ${ }^{24}$ Considering the obtained results and other studies, absorption is expected. Further studies are being developed to conclude about that.

\section{Conclusion}

In the present study, a coffee-like beverage from Q. cerris kernels was successfully produced and chemically characterized. In what concerns the kernel composition, a high content of fiber and carbohydrates (60.4\%) and the prevalence of $\alpha$-tocopherol as a principal vitamer deserve attention. On the other hand, the main constituents of $Q$. cerris kernels are lipids that are not extracted during the coffee-like preparation. Preliminary analysis by NMR spectroscopy revealed the presence, in the prepared beverage, of sugars as well as phenolic constituents, mainly tetragalloyl hexose and dihydroxymethylbenzoyl tetragalloylglucose. The coffee-like beverage revealed a high amount of total phenolics (2070.21 mg GAE per L) and flavonoid contents (285.27 CAE per L) as well as antioxidant activity (the $\mathrm{IC}_{50}$ determined for the $\mathrm{DPPH}$ assay was 271.61 $\mu \mathrm{g} \mathrm{mL} \mathrm{m}^{-1}$, while for FRAP the value was $203.11 \mu \mathrm{g} \mathrm{mL} \mathrm{m}^{-1}$ ). A high efficiency in the scavenging activity of ROS and RNS, especially $\mathrm{O}_{2}, \mathrm{H}_{2} \mathrm{O}_{2}$, $\mathrm{HClO}$ and ${ }^{\circ} \mathrm{NO}$, was observed. The extract was also screened for cell viability assays using two different intestinal cell lines (HT29-MTX and Caco-2), showing that concentrations between 0.1 and $1.0 \mu \mathrm{g} \mathrm{mL}^{-1}$ are safe and should be employed in further studies. Altogether, this study suggests that the coffee-like beverage prepared from $Q$. cerris kernels could be further explored as potentially health-promoting. Additionally, it is interesting to note that this plant material can be considered as a natural source of biocompounds with 
antioxidant potential and can be consumed as a beverage. Nevertheless, animal studies should be performed to ensure these optimistic results and definitive studies demonstrating direct health benefits on consumers should be conducted.

\section{Author contributions}

Conceived and designed the experiments: Diana Pinto, Santiago Diaz Franco, Ana Margarida Silva, Sónia Soares, Stefania Sut, and Francisca Rodrigues. Drafted or revised the manuscript: Sónia Soares, Francisca Rodrigues, Marijana Koskovac, Ksenija Kojicic, Stefano Dall'Acqua, and M. Beatriz P. P. Oliveira. Contributed reagents/materials/analysis tools: Snezana Cupara, Stefano Dall'Acqua, and M. Beatriz P. P. Oliveira.

\section{Acknowledgements}

Diana Pinto is thankful for the research grant from project UID/QUI/50006. Francisca Rodrigues is thankful for her postdoc research grant from the project Operação NORTE-01-0145FEDER-000011. This work received financial support from the European Union (FEDER funds through COMPETE), under the Partnership Agreement PT2020, and National Funds (FCT, Foundation for Science and Technology) through project LAQV/UID/QUI/50006/2013 and NORTE-07-0124FEDER-000069 - Food Science.

\section{References}

1 G. Baeza, B. Sarria, L. Bravo and R. Mateos, Polyphenol content, in vitro bioaccessibility and antioxidant capacity of widely consumed beverages, J. Sci. Food Agric., 2018, 98, 1397-1406.

2 A. F. Vinha, J. C. M. Barreira, A. S. G. Costa and M. Beatriz P. P. Oliveira, A new age for Quercus spp. fruits: Review on nutritional and phytochemical composition and related biological activities of acorns, Compr. Rev. Food Sci. Food Saf., 2016, 15, 947-981.

3 B. M. Popović, D. Štajner, R. Ždero, S. Orlović and Z. Galić, Antioxidant characterization of oak extracts combining spectrophotometric assays and chemometrics, Sci. World J., 2013, 2013, 134656.

4 S. Rakić, J. Kukić-Marković, S. Petrović, V. Tešević, S. Janković and D. Povrenović, Oak kernels - Volatile constituents and coffee-like beverages, J. Agric. Sci., 2018, 10, 117-124.

5 AOAC, in Official methods of analysis of AOAC International, ed. W. Horwitz, Gaithersburg, USA, 17th edn, 2012, ch. 32, p. 2 .
6 AOAC, in Official methods of analysis of AOAC International, ed. W. Horwitz, Gaithersburg, USA, 2012, p. 33.

7 K. Tontisirin, W. C. MacLean and P. Warwick, Food energy: Methods of analysis and conversion factors: Report of a technical workshop, FAO, 2003, 1-66.

8 R. C. Alves, S. Casal and M. B. P. P. Oliveira, Determination of vitamin e in coffee beans by HPLC using a micro-extraction method, Food Sci. Technol. Int., 2009, 15, 57-63.

9 V. L. Singleton and J. A. J. Rossi, Colorimetry of total phenolics with phosphomolybdic-phosphotungstic acid reagents, Am. J. Enol. Vitic., 1965, 16, 144-158.

10 R. Alves, A. Costa, M. Jerez, S. Casal, J. Sineiro, M. Núñez and M. B. P. P. Oliveira, Antiradical activity, phenolics profile, and hydroxymethylfurfural in espresso coffee: Influence of technological factors, J. Agric. Food Chem., 2010, 58, 12221-12229.

11 L. de Francisco, D. Pinto, H. Rosseto, L. Toledo, R. Santos, F. Tobaldini-Valério, T. Svidzinski, M. Bruschi, B. Sarmento, M. B. P. P. Oliveira and F. Rodrigues, Evaluation of radical scavenging activity, intestinal cell viability and antifungal activity of Brazilian propolis byproduct, Food Res. Int., 2018, 105, 537-547.

12 D. Almeida, D. Pinto, J. Santos, A. F. Vinha, J. Palmeira, H. N. Ferreira, F. Rodrigues and M. B. P. P. Oliveira, Hardy kiwifruit leaves (Actinidia arguta): An extraordinary source of value-added compounds for food industry, Food Chem., 2018, 259, 113-121.

13 I. F. F. Benzie and J. J. Strain, in Methods in Enzymology, ed. P. Lester, Academic Press, 1999, vol. 299, pp. 15-27.

14 E. H. Liu, L. W. Qi, B. Li, Y. B. Peng, P. Li, C. Y. Li and J. Cao, High-speed separation and characterization of major constituents in Radix Paeoniae Rubra by fast highperformance liquid chromatography coupled with diodearray detection and time-of-flight mass spectrometry, Rapid Commun. Mass Spectrom., 2009, 23, 119-130.

15 F. Marangi, D. Pinto, L. Francisco, R. C. Alves, H. Puga, S. Sut, S. Dall'Acqua, F. Rodrigues and M. B. P. P. Oliveira, Hardy kiwi leaves extracted by multi-frequency multimode modulated technology: A sustainable and promising byproduct for industry, Food Res. Int., 2018, 112, 184-191.

16 B. Ou, M. Hampsch-Woodill and R. L. Prior, Development and validation of an improved oxygen radical absorbance capacity assay using fluorescein as the fluorescent probe, J. Agric. Food Chem., 2001, 49, 4619-4626.

17 R. Nieto, M. Rivera, M. A. García and J. F. Aguilera, Amino acid availability and energy value of acorn in the Iberian pig, Livest. Prod. Sci., 2002, 77, 227-239.

18 S. Li, Y. Zhou, M. Liu, Y. Zhang and S. Cao, Nutrient composition and starch characteristics of Quercus glandulifera Bl. seeds from China, Food Chem., 2015, 185, 371-376.

19 A. S. G. Costa, R. C. Alves, A. F. Vinha, S. V. P. Barreira, M. A. Nunes, L. M. Cunha and M. B. P. P. Oliveira, Optimization of antioxidants extraction from coffee silverskin, a roasting by-product, having in view a sustainable process, Ind. Crops Prod., 2014, 53, 350-357. 
20 N. Rocha-Guzmán, J. A. Gallegos-Infante, R. N. GonzálezLaredo, R. A. Reynoso-Camacho, M. Ramos-Gómez, T. Garcia-Gasca, M. Rodríguez-Muñoz, S. GuzmánMaldonado, L. Medina-Torres and B. Lujan-García, Antioxidant activity and genotoxic effect on HeLa cells of phenolic compounds from infusions of Quercus resinosa leaves, Food Chem., 2009, 115, 1320-1325.

21 C. I. Gamboa-Gómez, L. E. Simental-Mendía, R. F. GonzálezLaredo, E. J. Alcantar-Orozco, V. H. Monserrat-Juarez, J. C. Ramírez-España, J. A. Gallegos-Infante, M. R. MorenoJiménez and N. E. Rocha-Guzmán, In vitro and in vivo assessment of anti-hyperglycemic and antioxidant effects of Oak leaves (Quercus convallata and Quercus arizonica) infusions and fermented beverages, Food Res. Int., 2017, 102, 690-699.

22 M. J. Rodrigues, V. Neves, A. Martins, A. P. Rauter, N. R. Neng, J. M. F. Nogueira, J. Varela, L. Barreira and L. Custódio, In vitro antioxidant and anti-inflammatory properties of Limonium algarvense flowers' infusions and decoctions: A comparison with green tea (Camellia sinensis), Food Chem., 2016, 200, 322-329.

23 C. Martins-Gomes, M. Taghouti, J. Schäfer, M. Bunzel, A. M. Silva and F. M. Nunes, Chemical characterization and bioactive properties of decoctions and hydroethanolic extracts of Thymus carnosus Boiss, J. Funct. Foods, 2018, 43, 154-164.

24 L. M. B. de Francisco, D. Pinto, H. C. Rosseto, L. A. S. de Toledo, R. S. Dos Santos, P. Costa, F. Rodrigues, M. Beatriz P. P. Oliveira, B. Sarmento and M. L. Bruschi, Development of a microparticulate system containing Brazilian propolis by-product and gelatine for ascorbic acid delivery: evaluation of intestinal cell viability and radical scavenging activity, Food Funct., 2018, 9, 4194-4206. 